\title{
Principles of Pediatric Pain Management during the End-of-Life Period
}

\author{
Stefan J. Friedrichsdorf ${ }^{a}$ John J. Collins ${ }^{b}$ \\ a Pain and Palliative Care Program, Children's Hospitals and Clinics of Minnesota, Minneapolis, Minn., USA; \\ ${ }^{b}$ Pain and Palliative Care Service, Children's Hospital at Westmead, Sydney, Australia
}

\section{Key Words}

Pediatric palliative care $\cdot$ Symptom management $\cdot$ Child $\cdot$

Terminal care $\cdot$ Pain control

\begin{abstract}
More than $80 \%$ of children with a life-limiting condition such as cancer or a neurodegenerative disease suffer from pain during their last week of life. This article reviews the principles of pediatric pain management and addresses characteristics and pitfalls of integrative and pharmacological therapies during the end-of-life period of a child. Providing a good pain management for a dying child is one of the many domains of pediatric palliative care and usually requires a holistic, multidisciplinary approach and the knowledge to apply appropriate analgesic drugs in combination with integrative nondrug therapies.

Copyright $\odot 2007$ S. Karger AG, Basel
\end{abstract}

The authors have made extensive efforts to ensure that treatments, drugs and dosage regimens in this article are accurate and conform to the standards accepted at the time of the publication. However, changes in information through continuing research and clinical experience and the possibility of human error warrant that the authors do not accept any responsibility for any loss or damage arising from actions or decisions based on information in this article: the ultimate responsibility for the treatment of patients and interpretation of published material lies with the medical practitioner.

\section{Introduction}

'Living means learning to die' has been attributed to various sources - Seneca, Montaigne, Sartre, or Schreiber, but its fundamental wisdom remains true well into the 21 st century. Only a few generations ago, it was common in the majority of families, for infants and children to die due to birth or postnatal complications or infections. Nowadays, the death of a child is a rare and catastrophic incident in industrialized countries, and in modern societies parents are not prepared to deal with it. Since the opening of the first children's hospice in Oxford (UK) in 1982, more and more countries and regions are introducing pediatric palliative care programs. Palliative care for children and young people with life-limiting conditions is an active and total approach to care, embracing physical, emotional, social and spiritual elements. It focuses on enhancement of quality of life for the child and support for the family and includes management of distressing symptoms, provision of respite and care through disease, death and bereavement [1]. Among the many domains of pediatric palliative care, the management of distressing symptoms, especially pain, is one of the most important - but can only be seen in the global picture of a holistic, multidisciplinary approach to the child, siblings and parents and cannot be limited to the application of drugs during the last days of life.

\section{KARGER}

Fax +41613061234 E-Mail karger@karger.ch www.karger.com
(C) 2007 S. Karger AG, Basel

1011-7571/07/0167-0010\$23.50/0

Accessible online at:

www.karger.com/mpp
Stefan J. Friedrichsdorf, MD

Pain and Palliative Care Program, Children's Hospitals and Clinics of Minnesota 2525 Chicago Avenue South, Minneapolis, MN 55404 (USA)

Tel. +1612813 6246, Fax +1 6128136358

E-Mail stefan.friedrichsdorf@childrensmn.org 

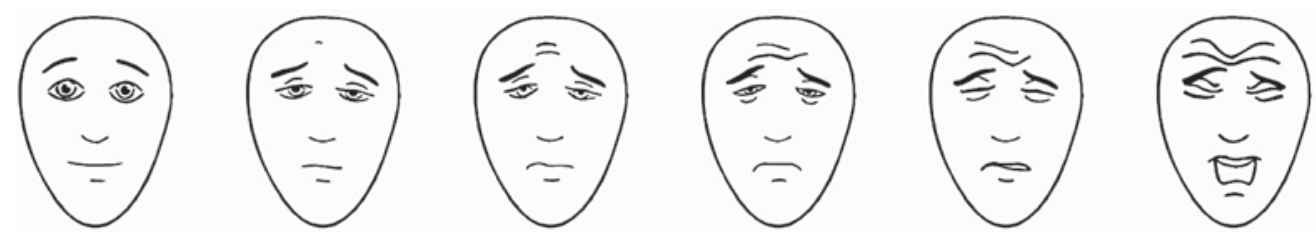

Fig. 1. The Faces Pain Scale Revised [30]. Reprinted with permission. Please check the website (www.painsourcebook.ca) for correct administration and translations into many languages of these instructions.

\section{Pain Assessment}

The majority of children dying from a life-limiting disease experience pain during their last week of life [25]. Regular pain assessment followed by appropriate analgesia is necessary to adequately relieve the children's suffering. Using one-dimensional self-report measures (e.g. visual analogue scales with the anchor points $0=$ no pain, $10=$ worst possible pain, or faces scale; fig. 1) [6-8] provide easy pain assessment of alert and responsive children communicating with their caregiver. For infants and children younger than 4 years of age, several pain assessment tools have been validated that require independent observers recording the physical behaviors, as well as the frequency of their occurrence [9]. Behavioral observation measures to assess pain in cognitively impaired children are increasingly used $[10,11]$.

\section{Integrative Pain Management}

State-of-the-art pain management in the 21st century demands that pharmacological management be no longer the sole approach to the management of a child's pain and suffering [12]. Supportive techniques, used on their own or together with pharmacological ones, include cognitive behavioral techniques (guided imagery, hypnosis, abdominal breathing, distraction) and physical methods (cuddle/hug, massage, transcutaneous electrical nerve stimulation, comfort positioning, heat, cold). Children cope better with pain and other distressing symptoms when they understand what is happening and when they are fully encouraged in the process to attain relief from their pain [13]. Comprehensive pain control at the end of life requires adjusting to the needs of the individual child and integrating methods of pain management.

Pediatric Pain Management

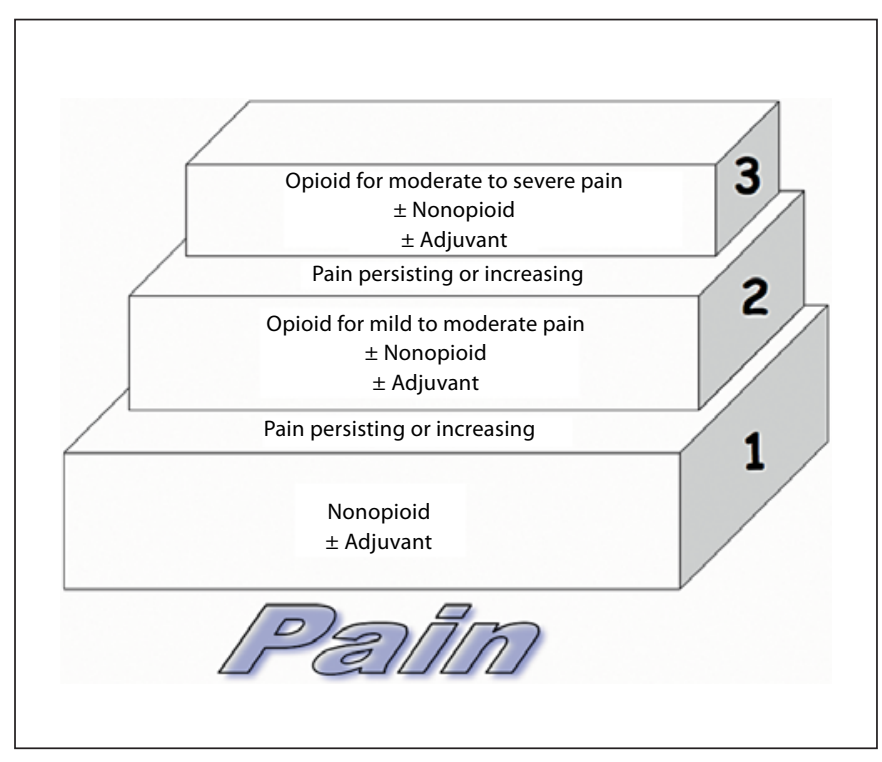

Fig. 2. The WHO three-step analgesic ladder [14].

\section{Pharmacological Pain Management}

There are several WHO principles [14] of the application of analgesia to children with life-limiting or terminal diseases described in what follows:

\section{Analgesic Ladder}

The choice of analgesic drugs should be based on the $\mathrm{WHO}$ analgesic ladder (fig. 2). An assessment of pain severity dictates the choice of analgesic. Severe pain requires strong pain medication, i.e. opioids. A child with severe pain should not slowly step up the ladder commencing with paracetamol, then later adding codeine before eventually changing to morphine. In this scenario, 
Table 1. Opioid analgesics: usual starting doses $[9,15]$

\begin{tabular}{|c|c|c|c|c|c|}
\hline Drug & $\begin{array}{l}\text { Equianalgesic } \\
\text { dose } \\
\text { (parenteral) }\end{array}$ & Starting dose intravenous & $\begin{array}{l}\text { Intravenous: } \\
\text { oral ratio }\end{array}$ & $\begin{array}{l}\text { Starting dose per os } \\
\text { (transdermal) }\end{array}$ & $\begin{array}{l}\text { Starting dose } \\
\text { controlled } \\
\text { release }\end{array}$ \\
\hline Morphine & $10 \mathrm{mg}$ & $\begin{array}{l}\text { bolus dose: } 50-100 \mu \mathrm{g} / \mathrm{kg} \\
\text { every } 2-4 \mathrm{~h} \\
\text { continuous infusion: } \\
10-30 \mu \mathrm{g} / \mathrm{kg} / \mathrm{h}\end{array}$ & $1: 3$ & $0.15-0.3 \mathrm{mg} / \mathrm{kg}$ every $4 \mathrm{~h}$ & $\begin{array}{l}0.45-0.9 \mathrm{mg} \\
\text { every } 12 \mathrm{~h}\end{array}$ \\
\hline Fentanyl & $100-250 \mu \mathrm{g}$ & $\begin{array}{l}\text { bolus dose: } 1-3 \mu \mathrm{g} / \mathrm{kg} \\
\text { (slowly over } 3-5 \mathrm{~min}- \\
\text { fast bolus may cause thorax } \\
\text { rigidity) } \\
\text { continuous infusion: } \\
1-2 \mu \mathrm{g} / \mathrm{kg} / \mathrm{h}\end{array}$ & $\begin{array}{l}1: 1 \\
\text { (intravenous to } \\
\text { transdermal) }\end{array}$ & $\begin{array}{l}25 \mu \mathrm{g} / \mathrm{h} \text { patch (must be on the } \\
\text { equivalent of at least } 30-60 \mathrm{mg} \\
\text { oral morphine/ } 24 \mathrm{~h} \text {, before } \\
\text { switched to patch) }\end{array}$ & $\mathrm{n} / \mathrm{a}$ \\
\hline Hydromorphone & $1.5 \mathrm{mg}$ & $\begin{array}{l}\text { bolus dose: } 15-20 \mu \mathrm{g} / \mathrm{kg} \\
\text { every } 4 \mathrm{~h} \\
\text { continuous infusion: } \\
5 \mu \mathrm{g} / \mathrm{kg} / \mathrm{h}\end{array}$ & $1: 5$ & $60 \mu \mathrm{g} / \mathrm{kg}$ every $3-4 \mathrm{~h}$ & $\begin{array}{l}180 \mu \mathrm{g} / \mathrm{kg} \\
\text { every } 12 \mathrm{~h}\end{array}$ \\
\hline Oxycodone & $5-10 \mathrm{mg}$ & $\mathrm{n} / \mathrm{a}$ & $\mathrm{n} / \mathrm{a}$ & $0.1-0.3 \mathrm{mg} / \mathrm{kg}$ every $4 \mathrm{~h}$ & $\begin{array}{l}0.3-0.9 \mathrm{mg} / \mathrm{kg} \\
\text { every } 12 \mathrm{~h}\end{array}$ \\
\hline Codeine & $120 \mathrm{mg}$ & $\mathrm{n} / \mathrm{a}$ & $\mathrm{n} / \mathrm{a}$ & $0.5-1 \mathrm{mg} / \mathrm{kg}$ every $3-4 \mathrm{~h}$ & $\mathrm{n} / \mathrm{a}$ \\
\hline Tramadol & $100 \mathrm{mg}$ & $\begin{array}{l}\text { bolus dose: } 1 \mathrm{mg} / \mathrm{kg} \\
\text { every } 3-4 \mathrm{~h} \\
\text { continuous infusion: } \\
0.25 \mathrm{mg} / \mathrm{kg} / \mathrm{h}\end{array}$ & $1: 1$ & $1 \mathrm{mg} / \mathrm{kg}$ every $3-4 \mathrm{~h}$ & $\mathrm{n} / \mathrm{a}$ \\
\hline
\end{tabular}

WHO step 3 (strong opioids) should have been commenced immediately.

\section{By the Clock}

Regular scheduling ensures a steady blood level, reducing the peaks and troughs of 'as needed' dosing. Commonly used opioid drug regimes include immediate-release oral morphine every $4 \mathrm{~h}$ or controlled-release morphine twice per day plus (for both strategies) 1/10-1/6 of the 24-hour morphine requirement as an hourly fast-release breakthrough pain medication as needed (table 1).

\section{By the Appropriate Route}

The oral route (or via nasogastric/percutaneous endoscopic gastrostomy tube) is convenient, noninvasive and usually preferred by the children and their caregivers, whereas the painful intramuscular application of pain medication is unnecessary and obsolete.
Rectal application is often unpopular and may deliver a wide variability in therapeutic blood levels through variable absorption.

Intranasal application of opioids is pain-free and safe [15]. Fentanyl and diamorphine can be diluted in normal saline solution ( $0.9 \%)$ and may be applied as a nasal spray or in drops. The pharmacokinetic profile of intranasal fentanyl seems to be similar to intravenous fentanyl [16]. Intranasal fentanyl does not irritate the nasal mucous membrane and has only minimal ciliotoxic properties $[17,18]$. Reported intranasal fentanyl doses in children $(1-1.5 \mu \mathrm{g} / \mathrm{kg})$ are equal to or only slightly above suggested intravenous doses $[17,19]$ (table 1).

Transdermal fentanyl patches and transdermal buprenorphine patches are contraindicated for acute pain management due to a long onset time (it may take more than $60 \mathrm{~h}$ to reach peak concentrations in children) [20, 21], inability to rapidly titrate drug delivery and long 
elimination half-life. Transdermal opioids have their role in chronic, stable pain.

The Actiq ${ }^{\circledR}$ lozenge is a solid drug matrix with berry flavor providing oral transmucosal fentanyl citrate. Due to fentanyl's high lipophilicity, absorption across the oral mucosa directly into the systemic blood is rapid. Oral transmucosal fentanyl citrate has been used for children 3 years of age and above. Recent studies in opioid-naïve children showed typical opioid side effects of oral transmucosal fentanyl citrate, including respiratory depression. Earlier pediatric trials, which reported higher rates of respiratory depression, either used high doses of oral transmucosal fentanyl citrate $(>20 \mathrm{mg} / \mathrm{kg})$ and/or treated cardiosurgical patients, including children with cyanotic heart defects [22]. Some pediatric trials reported nausea and vomiting commonly, others rarely or not at all. Due to these adverse effects, the indications for oral transmucosal fentanyl citrate have recently been changed. Currently, oral transmucosal fentanyl citrate is indicated exclusively for the treatment of breakthrough pain in cancer patients and is no longer used for sedation or premedication. If used for this purpose, certain guidelines should be followed [23].

The intravenous application of opioid may be feasible, especially when there is a central line in place. Patientcontrolled analgesia/nurse-controlled analgesia pumps (e.g. morphine, fentanyl, hydromorphone, methadone) with a continuous background and an as-needed bolus often provide excellent pain management. Alternatively, opioid analgesics can be applied subcutaneously in the same dose as an intravenous administration. Many children and their parents we cared for were comfortable in terminal care with a subcutaneous or intravenous patient-controlled analgesia/nurse-controlled analgesia pump providing opioids for the management of pain and dyspnea in home settings.

\section{With the Child}

The analgesic treatment should be individualized according to the child's pain, response to treatment, and frequently reassessed and modified as required. Some children may require extremely high doses of opioids (sometimes more than 500 times the starting dose) to control severe pain. Adjuvant drugs (e.g. amitriptyline, gabapentin, ketamine, benzodiazepines, bisphosphonates) may be appropriate in the pain management of the individual child. Pediatric pain specialists should be consulted before adjuvant drugs are commenced. On a few occasions, we have been confronted with severely cognitively impaired children with mitochondrial diseases, who, although showing signs of severe pain, did not benefit from opioid analgesia. Those children improved significantly on the atypical antipsychotic drug olanzapine, eventually requiring little or no pain medication, which suggests that possibly a very abnormal brain was perceiving and interpreting stimuli in an abnormal way.

\section{Nonopioids}

Frequently used nonopioids include paracetamol (acetaminophen), ibuprofen and metamizole (dipyrone), the latter not available in most English-speaking countries. Paracetamol (10-15 mg/kg p.o./p.r. every 4-6 h; dose limit: $<2$ years: $60 \mathrm{mg} / \mathrm{kg} / \mathrm{day},>2$ years: $90 \mathrm{mg} / \mathrm{kg} /$ day) is generally well tolerated by children and lacks gastrointestinal and hematological side effects. Significant hepatotoxicity [24] is rare, but careful attention to dosing is paramount.

Ibuprofen $(10 \mathrm{mg} / \mathrm{kg}$ p.o. three to four times a day; dose limit: 2,400 mg/day) has the least gastrointestinal side effects among the nonsteroidal anti-inflammatory drugs. It should be used with caution with hepatic or renal impairment, history of gastrointestinal bleeding or ulcers and it may inhibit platelet aggregation.

Metamizole (dipyrone) is widely used in Europe in pediatric pain management and seems to rank with its potency between a nonsteroidal anti-inflammatory drug and a 'weak opioid'. The antispasmodic effects of metamizole $(15 \mathrm{mg} / \mathrm{kg}$ p.o., i.v. as short infusion, four times a day) may be helpful in certain types of abdominal pain. Agranulocytosis is a very rare side effect, albeit not specific for metamizole among nonopioids.

\section{Opioids}

Codeine and tramadol are frequently used for mild to moderate pain and are so-called 'weak opioids' due to their ceiling effect (increasing the above-recommended dosing does increase adverse effects, but does not increase analgesia). Codeine not only has a variable bioavailability (15-80\%), but also produces its analgesic effect only through its metabolite morphine. This pathway depends on the activity of the cytochrome P450 enzyme 2D6. Slow metabolizers (in white Caucasians 10\%, in Chinese 30\%) receive poor analgesia by codeine. This genetic polymorphism exists to a lesser degree in tramadol as well. The analgesic strength of tramadol is augmented by an additional effect in inhibiting monoamine neurotransmitter reuptake and it has a potency intermediate between codeine and morphine [25]. Tramadol is the preferred oral and intravenous opioid for mild to moderate pain in many non-English-speaking countries (e.g. Germany). 
'Weak' and 'strong' opioids should not be combined due to an unfavorable side effect profile.

The most frequently used 'strong' opioid is morphine. Opioid-associated side effects (e.g. constipation, pruritus, nausea) should be expected and treated accordingly. For recommended starting doses, see table 1 . An opioid rotation may be necessary if dose-limiting opioid toxicity occurs [26]. This is necessary in about $10-20 \%$ of the children provided with opioids by the Pain and Palliative Care Team at the Children's Hospital at Westmead, Sydney, Australia. It was observed that a switch from one opioid to another is often accompanied by a change in the balance between analgesia and side effects [27]. A favorable change in the opioid analgesia to side effect profile will be experienced if there is less cross-tolerance at the opioid receptors mediating analgesia than at those mediating adverse effects [28]. If changing between opioids with a short duration of action is necessary because of incomplete cross-tolerance, start the new opioid at 50\% of the equianalgesic dose and titrate to effect. Even if a child may become unconscious during the last days of life due to the underlying disease (and not because of opioid toxicity), ceasing regular opioid analgesic drugs may provoke unpleasant withdrawal.

\section{Obstacles}

Many myths remain and may be responsible for inadequate pain management of many children in palliative care. Especially infants, very young, severely im- paired children and teens often do not receive sufficient analgesia because their discomfort is different from that of adults. It is fallacious to believe that children's nervous systems are immature and therefore unable to perceive and experience pain. All available data suggest that those theories are wrong [29]. The application of an opioid to treat pain or dyspnea does not hasten a child's death if titrated to effect. The correct provision of opioids for symptom management not only improves the quality of life of a dying child significantly, but often prolongs the end-of-life period due to the improved quality of life.

\section{Conclusions}

Children in severe pain quite often need strong pain medication, i.e. morphine or other strong opioids. A dose-limiting side effect may require an opioid rotation. Pediatric evidence and experience also support novel routes of opioid application: transmucosal, transdermal and intranasal opioid applications are well tolerated by children, and are effective and safe. But neither transdermal nor transmucosal opioids must be used in opioid-naïve children and transdermal opioids are contraindicated in acute pediatric pain management. Providing effective pain management for a dying child usually requires a holistic, multidisciplinary approach and the knowledge to apply appropriate analgesic drugs in combination with integrative nondrug therapies.

\section{References}

1 Association for Children with Life-Threatening or Terminal Conditions and Their Families and The Royal College of Paediatrics and Child Health: A Guide to the Development of Children's Palliative Care Services, ed 2. Bristol, Association for Children with Life-Threatening or Terminal Conditions and Their Families, 2003.

2 Dangel T: Domowa opieka paliatywna nad dziecmi w Polsce. Warsaw, Department of Palliative Care, Institute for Mother and Child, 2001.

3 Drake R, Frost J, Collins JJ: The symptoms of dying children. J Pain Symptom Manage 2003;26:594-603.

4 Goldman A: Symptoms and suffering at the end of life in children with cancer - correspondence. N Engl J Med 2000;342:19971999.
5 Wolfe J, Grier HE, Klar N: Symptoms and suffering at the end of life in children with cancer. N Engl J Med 2000;342:326-333.

6 Jay SM, Elliott C, Siegal S: Cognitive, behavioral, and pharmacologic interventions for children's distress during painful medical procedures. J Consult Clin Psychol 1987;55: $860-865$.

7 Elliott C, Jay SM, Woody P: An observational scale for measuring children's distress during medical procedures. J Pediatr Psychol 1987; 12:543-551.

8 Kuttner L, Bowman M, Teasdale M: Psychological treatment of distress, pain and anxiety for children with cancer. J Dev Behav Pediatr 1988;9:374-381.

9 Denecke H, Hünseler C: Messen und Erfassen von Schmerz; in Zernikow B (ed): Schmerztherapie bei Kindern, ed 2. Berlin, Springer, 2003, pp 51-79.
10 Solodiuk J, Curley MA: Pain assessment in nonverbal children with severe cognitive impairments: the Individualized Numeric Rating Scale (INRS). J Pediatr Nurs 2003;18: 295-299.

11 Collignon P, Giusiano B: Validation of a pain evaluation scale for patients with severe cerebral palsy. Eur J Pain 2001;5:433-442.

12 Kuttner L: Integrative methods to relieve pain and suffering; in Goldman A, Hain RDW, Liben S (eds): Oxford Textbook of Palliative Care for Children. Oxford, Oxford University Press, 2006.

13 Kuttner L: Mind-body methods of pain management. Child Adolesc Psychiatr Clin N Am 1997;6:783-795.

14 World Health Organization: Cancer Pain Relief and Palliative Care in Children. Geneva, World Health Organization, 1999. 
15 Yaster M, Kost-Byerly S, Maxwell LG: Opioid agonists and antagonists; in Schechter NL, Berde CB, Yaster M (eds): Pain in Infants, Children, and Adolescents, ed 2. Philadelphia, Lippincott Williams \& Wilkins, 2003, pp 181-224.

-16 Galinkin JL, Fazi LM, Cuy RM, Chiavacci RM, Kurth CD, Shah UK, Jacobs IN, Watcha MF: Use of intranasal fentanyl in children undergoing myringotomy and tube placement during halothane and sevoflurane anesthesia. Anesthesiology 2000;93:13781383.

-17 Manjushree R, Lahiri A, Ghosh BR, Arpita L, Handa K: Intranasal fentanyl provides adequate postoperative analgesia in pediatric patients. Can J Anaesth 2002;49:190-193.

18 Peng PWH, Sandler AN: A review of the use of fentanyl analgesia in the management of acute pain in adults. Anesthesiology 1999; 90:576-599.

19 Borland ML, Jacobs I, Geelhoed G: Intranasal fentanyl reduces acute pain in children in the emergency department: a safety and efficacy study. Emerg Med (Fremantle) 2002; $14: 275-280$
20 Collins JJ, Dunkel IJ, Gupta SK, Inturrisi CE, Lapin J, Palmer LN, Weinstein SM, Portenoy RK: Transdermal fentanyl in children with cancer pain: feasibility, tolerability, and pharmacokinetic correlates. J Pediatr 1999; 134:319-323.

21 Christensen ML, Wang WC, Harris S, Eades SK, Wilimas JA: Transdermal fentanyl administration in children and adolescents with sickle cell pain crisis. J Pediatr Hematol Oncol 1996;18:372-376.

22 Friedrichsdorf S: Fentanyl in pediatric pain management - Novel routes of administration. Suffering Child 2004;8:24-29.

23 Portenoy RK, Payne R, Coluzzi P, Raschko JW, Lyss A, Busch MA, Frigerio V, Ingham J, Loseth DB, Nordbrock E, Rhiner M: Oral transmucosal fentanyl citrate (OTFC) for the treatment of breakthrough pain in cancer patients: a controlled dose titration study. Pain 1999;79:303-312.

24 Heubi JE, Barbacci MB, Zimmerman HJ: Therapeutic misadventure with acetaminophen: hepatotoxicity after multiple doses in children. J Pediatr 1998;132:22-27.
25 Hain RDW, Miser A, Devins M, Wallace HB: Strong opioids in pediatric palliative medicine. Paediatr Drugs 2005;7:1-9.

26 Drake R, Longworth J, Collins JJ: Opioid rotation in children with cancer. J Palliat Med 2004;7:419-422.

27 Galer BS: Individual variability in the response to different opioids. Pain 1992;49: 87-91.

28 Portenoy RH, Gebhart GF, Hammond DI, Jensen TS: Opioid tolerance and responsiveness: research findings and clinical observations; in Gebhart (ed): Progress in Pain Research and Management. Seattle, IASP Press, 1994, pp 615-619.

29 Schechter NL, Berde CB, Yaster M: Pain in infants, children, and adolescents - An overview; in Schechter NL, Berde CB, Yaster M (eds): Pain in Infants, Children, and Adolescents, ed 2. Philadelphia, Lippincott Williams \& Wilkins, 2003, pp 3-18.

30 Hicks CL, von Baeyer CL, Spafford P, van Korlaar I, Goodenough B: The Faces Pain Scale-Revised: toward a common metric in pediatric pain measurement. Pain 2001;93: 173-183. 